\title{
ENTRE LETRAS, O MUNDO
}

\section{ENI PUCCINELLI ORLANDI ${ }^{1}$}

\author{
Programa de Pós-Graduação em Ciências da Linguagem \\ Universidade do Vale do Sapucaí \\ Av. Pref. Tuany Toledo, 470 - 37550-000 - Pouso Alegre - MG - Brasil
}

enip@uol.com.br

Resumo. Este texto interroga o que é fazer Letras no mundo atual, mundo feito de contradições, mundo da quantidade, das tecnologias, da chamada sociedade do conhecimento, dividindo seu espaço com o empreendedorismo. Marcas da mundialização por toda parte, em uma sociedade que se balança historicamente entre o multilinguismo e a língua única; entre o analfabetissmo oficial e as expectativas do digital, que se repete, mas que também promove a invenção do grafismo da letra e se expande vigorosamente, sem pedir licença. Nestas condições, nos perguntamos: que sujeito do conhecimento estamos formando, pelo trabalho com a lingua, com as línguas, com a literatura, e como ele afetará a sociedade com seu trabalho, com sua prática? Nosso objetivo é, assim, ao instalar um Curso de Letras, compreendermos em forma atual, como se institucionaliza a relação dos sujeitos com a(s) língua(s) e que parte aí tomam as Instituições, o Estado e os discursos que ele produz. E como podemos nos mexer nesta conjuntura? Desse modo, procuramos mostrar como o estudo da língua, e de seu conhecimento, pode nos "falar" de nossa sociedade e de nossa história, assim como do que resulta como ideias que se constituem e nos acompanham ao longo dessa história. Produzir conhecimento sobre Letras é mexer com o que elas significam, ao nos significarem, em sua omnipresença no mundo. E isto traz uma enorme possibilidade de ação como também uma grande responsabilidade de decisões na prática deste conhecimento.

Palavras-chave: Letras; sociedade; sujeito; conhecimento; linguagem.

\begin{abstract}
This text interrogates what it is to do Letters in today's world, world made of contradictions, world of quantity, of technologies, of the so-called knowledge society, whose space is divided with entrepreneurship. Imprints of globalization everywhere, in a society that historically balances between multilingualism and the single language; between official illiteracy and digital expectations, which is repeated, but also promotes the invention of letter graphics and expands vigorously, without asking permission. In these conditions, we ask ourselves: what subject of knowledge are we forming, by working with language, with languages, with literature, and how will it affect society with its work, with its practice? Our objective is, therefore, when installing a Course of Letters, to understand, in a current way, how the relations between subjects and language(s) become institutionalized and what part in this process is due to Institutions, to the State and to the discourses that they produce. And how can we move in this situation? In this
\end{abstract}

\footnotetext{
${ }^{1}$ Coordenadora e docente do Programa de Pós-graduação em Ciências da Linguagem.
} 
way, we try to show how the study of language and the study of its knowledge can "tell" us about our society and our history, as well as about what results as ideas that are constituted and accompany us throughout that history. To produce knowledge about Letters is to deal with what they signify while signifying us in their omnipresence in the world. And this brings an enormous possibility of action as well as a great responsibility while making decisions within the practice of this knowledge.

Keywords: Letters; society; subject; knowledge; language.

\section{CONHECIMENTO SOBRE A LÍNGUA E SUA CONSTITUIÇÃO}

Iniciei um livro sobre Ciência da Linguagem e Política (2014) com uma epígrafe de Graciliano Ramos (1953) que diz: "começamos oprimidos pela sintaxe e acabamos às voltas com a Delegacia de Ordem Política e Social, mas, nos estreitos limites a que nos coagem a gramática e a lei, ainda nos podemos mexer".

Do mesmo modo, neste meu livro, o que procuro mostrar é que os estudos de linguagem sempre se fazem em uma conjuntura político-social que determina de muitas maneiras as escolhas de projetos de pesquisa e de filiações teóricas que configuram o modo e o sentido com que a linguagem é concebida e estudada. No entanto, algo sempre vaza, resiste e foge para caminhos ainda não explorados, para espaços em que podemos nos mexer. E são estes espaços que procuramos explorar com essa nossa proposta de um curso de Letras. Um curso em que os alunos possam se mexer, que nós, docentes, possamos nos mexer com eles e com o modo como as Letras têm sido consideradas, muitas vezes, in vitro, ou seja, fora do real em que a linguagem funciona e que implica os sujeitos, a sociedade, a história e nossa experiência do mundo, no mundo. É a este real que estamos atentos, no conhecimento de linguagem que propomos.

Por isso, minha pergunta inaugural, desta aula, é: O que é fazer Letras no mundo atual? Um mundo cheio de contradições, que se diz multilíngue, ao mesmo tempo em que funciona no imaginário de uma língua única, o inglês, que tem uma enorme força arregimentadora; um mundo digital, ao lado de um enorme contingente analfabeto - sem acesso ao funcionamento oficial das letras, ou melhor, da Letra -, um mundo que, na falta da Letra oficial, inventa o grafismo (pixação, tatuagem, piercing) e se expande vigorosamente. Um mundo em que a Ciência é ultra idealizada, mas em que se investe mais na capacitação, para o mercado e o trabalho, do que na formação para um conhecimento real em que o sujeito do conhecimento ganhe independência e capacidade de escolha, desenvolvendo não só a ciência, a técnica, mas também a sensibilidade e a iniciativa, a inventividade.

Pois bem, é em um mundo assim que, em nossa equipe do PPGCL (Programa de Pós-Graduação em Ciências da Linguagem), da UNIVẢS (Universidade do Vale do Sapucaí), nos arriscamos a escolher um modo de pensar Letras, de nos inscrevermos em campos teóricos que valorizam a formação. Isso implica pensar os processos e a constituição da língua, das línguas, na sociedade e na história, em seus espaços de funcionamento. Isto implica em pensar sujeitos falando e não apenas a língua fechada em si mesma. Praticamos o que um autor, como Pêcheux, de modo bem-humorado, refere ao 
dizer: o idiota, ao lhe mostrarmos a lua, olha o dedo. E acrescenta: por que não? Pois é isto que fazemos: não ficamos só com os resultados, mas observamos os processos. Olhamos o dedo que nos indica a lua para sabermos que sentidos estão sendo atribuídos à lua.

Assim, nos perguntamos, ao escolhermos uma teoria e não outra, que política de língua está implicada por esta ou aquela teoria. Como a produção do conhecimento sobre e da língua resulta em uma organização social do trabalho sobre a língua, nos perguntamos: que sujeito do conhecimento estamos formando, e como ele afetará a sociedade com seu trabalho. Ainda faz parte de nossos objetivos compreendermos como se institucionaliza a relação dos sujeitos com a língua, e que parte aí tomam as Instituições, o Estado e os discursos que ele produz, e que se encarregam desta sua formação.

Pensando que, ao ensinar, nos apropriamos de instrumentos, de ferramentas para tal, interessa-nos questionar a produção desses instrumentos enquanto tecnologias que representam a língua para seus falantes, em seu conjunto. Instrumentos tão simples como dicionários ou gramáticas, e mesmo manuais, sejam no modo tradicional, sejam digitalizados, são ferramentas, são tecnologias que carregam um sentido para o que ensinamos e para o que aprendemos. Não só estes instrumentos, mas, também, a escrita teórica - sobre a língua - têm parte fundamental no conhecimento das Letras, porque a própria escrita sobre nossa língua pode ou não desestabilizar a visão da história como algo estável e já feito, consumado, sendo então a história não sujeita a interpretações, a mudanças. A forma histórica de nosso sujeito social brasileiro pode ser apreendida no modo como a língua é ensinada (olhar o dedo!). Isso quanto ao imaginário da cidadania. A forma da gramática adquire, para nós, outro sentido (que não o de prisão, porque nos mexemos) e não é demais perguntar: a que imaginário, a que imagem de cidadania corresponde hoje a forma de conhecimento da língua que produzimos e que ensinamos ou praticamos, representada na gramática? Esta gramática é compatível com o estado social da língua atual?

Isto tudo que viemos de dizer se reporta ao fato de que sabemos que a linguagem não é transparente, embora pareça ${ }^{2}$. E o modo como chegamos até ela, como a percebemos, como a concebemos terá um peso enorme no seu conhecimento e em seu ensino.

Pensando a língua portuguesa, ou língua brasileira (2009) como a denomino, considero que através do conhecimento da maneira como nossa língua foi-se constituindo, e, através das formas que adquire o saber a respeito dela, podemos melhor conhecer a história de nosso país e seus sujeitos cidadãos. Em vez de fazer a história da sociedade brasileira, aí incluindo a língua, procuramos mostrar como o estudo da língua, e de seu conhecimento, pode nos "falar" da nossa sociedade e da nossa história, assim como do que resulta como ideias que se constituem e que nos acompanham ao longo de nossa história. Desse modo podemos melhor nos situarmos em relação ao que nos atribuem como professores: saber a nossa língua e ensiná-la. E também saber, no caso de uma língua estrangeira, no nosso caso, o inglês, não só sua estrutura, mas também seu

\footnotetext{
2 Basta para pensarmos em sua não transparência, observar a diferença que se instala no processo de significação de palavras como Terra/terra; não só na diferença entre maiúscula (Planeta/ chão), mas quando se trata de diferentes posições-sujeitos: o índio, o proprietário, o sem-terra.
} 
funcionamento na relação com a nossa e com as outras línguas, no contexto mundial do polilinguismo. Para ser um profissional das Letras, não basta saber uma língua, pois é preciso saber que a sabemos. E podemos observar isto através das ferramentas que construímos, que usamos, e do modo como a ensinamos.

Para terminar esta introdução, gostaria de referir a uma distinção que costumo fazer e que acho muito relevante, sobretudo quando pensamos em uma língua, como a nossa, que se forma no processo de colonização. É a distinção entre língua fluida e língua imaginária.

Existe língua e existem línguas, dizem os autores Pêcheux e Gadet (1981). E esta é uma diferença metodológica a que eles atam a divisão entre a língua gramatical e o que chamam o corpo pleno da língua. Em meus termos, e pensando a língua brasileira em relação à portuguesa e às línguas indígenas, como parte de nossa formação social (a que, mais tarde agregamos as de imigração e de fronteiras), defini a língua imaginária como sistema fechado, normas, artefato do linguista com sua sistematização (mas também dos missionários e assemelhados), ao passo que a língua fluida é a língua no mundo, sem regras que a aprisionem, língua no acontecimento do significar, na relação de homens com homens, sujeitos e sujeitos. A língua fluida não se deixa imobilizar nas redes do sistema e de fórmulas. Língua que se mexe. E o que aprendi é que não se pode pensar uma sem a outra. Pois somos plurais. No mundo é sempre preciso pensar a relação do sujeito consigo mesmo, sem deixar de pensar sua relação com o outro, os outros, o Outro (memória que constitui o sujeito). Pensar estas relações permite-nos compreender as intrincadas relações entre noções como língua materna, língua nacional, língua estrangeira etc.

Esta parte de minha exposição está muito ligada a um grande projeto internacional, de que fazemos parte no Brasil, e que trata justamente da constituição do saber sobre as línguas. E que julguei interessante trazer, para situá-los em relação ao fato de que as ideias, que se produzem sobre as línguas, não brotam por si mesmas, nem caem do céu, elas fazem parte da maneira mesmo como as pensamos e, sobretudo, como as falamos: presos em estruturas fixadas para sempre ou no movimento de seu funcionamento nas diferentes conjunturas sociais e históricas em que os sujeitos são parte importantíssima de sua existência. Da sua língua e das línguas. Porque mesmo que haja muitas diferenças tanto pessoais, como regionais etc., falamos a mesma língua, mas falamos diferente. E aqui acentuo: a mesma língua. Como, pois, produzir um conhecimento que possa ser conjugado por todos os que a falam, sem perder suas especificidades, e sem se perder em sua fragmentação? A resposta, que podemos dar de forma geral ainda, neste nosso primeiro encontro, é que devemos apostar na formação do sujeito do conhecimento de Letras e não meramente em sua "capacitação". Não o reduzimos assim a sua habilidade para o trabalho e o mercado, na forma profissionalizante, mas o expomos a formas de conhecimento que abrangem manifestações da língua que se movem, são dinâmicas. E, paradoxalmente, por pensarmos em sua formação, e não apenas em sua capacitação profissional para o imediato, abrem-se perspectivas de trabalho mais amplas e modifica-se a sua própria relação com sua profissão. Ele passa a compreender os efeitos de sua formação na sociedade e os efeitos da sociedade sobre suas formas de conhecimento. Passa a não só repetir, mas a ser inventivo, a ser mexer, e a ter independência em suas iniciativas. 


\section{SOMOS SUJEITOS SIMBÓLICOS, SOCIAIS E HISTÓRICOS}

Há mitos sobre a linguagem em abundância. Eu vou referir a um de que gosto muito e que aprendi com o prof. Cavalcante, professor de grego da USP. Diz ele que o homem vivia em perfeita harmonia com a natureza. Havia uma ligação de continuidade entre homem e natureza. Por razões que se desconhece, de repente, homem e natureza se separaram. Do lugar desta separação, para que não houvesse aí um vazio, nasce a linguagem. $\mathrm{O}$ que significa dizer que a linguagem se constitui para preencher uma falta.

Mitos e lendas à parte, podemos afirmar, sem dúvida, que nascemos condenados a falar, ou melhor, a significar. Ou seja, somos constituídos pela linguagem, somos seres simbólicos. Desse modo, também faz parte de nossa relação com o mundo interpretar: a tudo temos de "dar" sentido. Diante do non sens, ficamos incomodados. "O que isso significa?" é uma nossa pergunta permanente, muitas vezes inconsciente. Assim como também não sabemos por que é este sentido e não outro que nos afeta. A nossa necessidade de falar, segundo o mito que referi, nasce dessa falta de relação já resolvida com o mundo, com a natureza e com nossos outros (pela linguagem).

A linguagem pode ser assim considerada como parte da natureza humana. Tanto é que, se, a partir de certa idade, a gente não fala, isso é motivo de preocupação.

Quanto a sua natureza, a linguagem pode ser pensada como um conjunto de regras, de injunções, de formas a se repetir e analisar, mas também pode ser pensada como algo transformador e que se transforma.

Esta é nossa perspectiva: pensar a linguagem como mediação entre o homem e a realidade natural e social. Como elemento transformador do homem e de sua realidade natural e social. Em retorno, também ela se transforma.

E assim é que vemos que, ao trazer a linguagem para esta perspectiva, é que podemos compreender como somos sujeitos simbólicos (significamos e ao significar nos significamos) e também sociais e históricos. Porque somos sujeitos de linguagem. Esta é uma característica de nossa humanidade, que carrega de sentidos tanto as ferramentas com que a trabalhamos como as marcas reais, sociais, históricas, políticas, psíquicas que essa nossa humanidade convoca.

Para entender a importância do profissional de Letras no mundo contemporâneo, basta olharmos à nossa volta e ver como se carregam os sentidos com seus conflitos, violência, des-compreensão, guerra de informação, indistinção, equívocos, mas também paz, relações bem-sucedidas de sociabilidade, amizade, novos sentidos. Ao mesmo tempo em que a linguagem, em suas diferentes e múltiplas formas, é omnipresente. Está em toda parte produzindo seus efeitos. Produzir conhecimento sobre Letras - língua e literatura, mas também suas manifestações conexas - hoje, traz uma enorme possibilidade de ação no mundo e também uma grande responsabilidade de escolhas na prática deste conhecimento, em sua profissionalização. Porque o mundo atual é um mundo definido pelo conhecimento e pelas múltiplas formas de linguagem. Compreender a língua, as línguas, é estar entre as letras, no mundo. 


\section{DA LETRA E DAS LETRAS}

Saber ler-e-escrever é uma injunção, uma obrigação, em nossa sociedade letrada, ocidental, cristã. Mas pode-se olhar por outro lado e vemos, então, que é também uma necessidade para o sujeito: é o jeito que ele tem de significar o mundo, se significando nele. E saber "dar" sentido ao que ouve, ao que lê, ao que vê.

Como injunção, sabemos que nossa sociedade se divide entre os que têm acesso às letras, na Escola, e os que não têm acesso. Como tenho dito, a Escola (a escolarização), porque é uma instituição, faz efeito não só em seu espaço próprio, mas também fora dele. Numa sociedade capitalista, em que a escolaridade é parte do valor atribuído à pessoa, quem não foi, ou não está na escola, também é atingido por este valor. No caso, de forma negativa. Dividimos nossa sociedade entre indivíduos escolarizados e não escolarizados. É nessa conjuntura que a questão da língua se impõe com sua força e sentido. A língua como condição de desenvolvimento de qualquer discursividade. Condição que hoje se transmuda, muitas vezes, no digital. Que também é uma forma de escrita. E aí tocamos em algo fundamental: a escrita.

A língua, o conhecimento da língua está ligado fundamentalmente à escrita. Sabemos que a escrita não é mera transcrição da oralidade ${ }^{3}$. Em nosso caso, com uma história de colonização linguística, não levar em conta, por exemplo, que temos duas formas de oralidade (ORLANDI, 2002) derivadas de duas histórias diferentes faz com que se queira fazer o aluno passar, com violência, de uma oralidade que faz parte da história de sua língua para uma escrita que tem uma oralidade que corresponde a "outra" história. Isto é impossível. O resultado não é um fracasso, como dizem, é uma inconsistência histórica, é resistência ao que não faz sentido ${ }^{4}$.

Mas voltemos à escrita e sua importância para a escolarização, mas também para a necessidade dos sujeitos se construírem autores. Modernos. E o autor moderno está preso à invenção da imprensa, pois esta marca o nascimento do texto moderno, o definitivo, o fixado, o repetível. No século XIX se expande essa noção de texto. E valoriza-se a noção de autor. Tudo isso ligado à escrita. À Letra (língua). Às Letras (literatura). A escrita modifica nossa relação com nossa língua, modifica até mesmo a língua. Portanto, não podemos desconhecer o que nos liga e que efeitos produz esta relação: língua, texto, escrita.

Vale lembrar que a noção de texto é ligada, sobretudo, à produção de sentidos. Eu o considero uma unidade de sentido em relação a uma situação. Exemplo: um A (marca de feminino), ou um $\mathrm{O}$ (masculino), na porta de um banheiro. Como vou dizer mais

\footnotetext{
${ }^{3}$ Cerquiglini, especialista em filologia medieval, diz que a invenção da imprensa, que fixa a escrita e a reproduz em muitas vezes, igual (cópia fiel), com seu autor, sempre foi um sonho da humanidade. Justamente porque "toda cópia é alteração", "transcrever trai, porque a mão humana se desprende desajeitadamente da posse fugitiva dos sentidos.

${ }^{4}$ Desconhece-se que no início a língua falada no Brasil era a Língua Geral, e a língua escrita era o Latim e depois foi o português de Portugal, já que a língua geral e outras manifestações locais não mereceram a legitimação de sua escrita, ao contrário, foram apagadas social e historicamente. Isso pesa na nossa passagem da oralidade para a escrita. Porque permanece um imaginário mal resolvido, na imagem que temos da escrita em nossa sociedade brasileira (relação Estado/Nação e Sociedade), pois passamos a fazer parte da filiação ao latim, com nossa língua nacional ocidental.
} 
adiante, a noção de texto, hoje, com as tecnologias de linguagem, as redes sociais etc tem mudado muito, mas se marca pela sua estrutura e funcionamento.

A filologia medieval (CERQUIGLINI, 1989) nos mostra que a escrita não produz a variante, ela é ela mesma variança. Desliza, retorna, rediz. Se, desde o século XV (com a escrita) e, sobretudo, nos séculos XVIII e XIX reinam os ideais de fixação, de mecanização da escrita única e multiplicada, aos poucos, a própria escrita e os textos começam a se movimentar em suas formas e em seus efeitos nas relações entre sujeitos e dos sujeitos com a linguagem, as linguagens. De novo, algo volta a se mexer. E também o conhecimento da linguagem desliza, desloca-se, com a noção de discurso, definido como efeito de sentidos entre locutores.

A língua deixa de ser vista como sistema fechado, mas como sujeita a falhas, sendo estas o lugar dos possíveis, da diversidade, da invenção. Abre-se para o equívoco, o inusitado, o que ainda virá a ser. Também aprendemos, na observação dos textos, que o que há são versões. A variança é a própria condição de existência do texto, da escrita. E nos encontramos, por essa via, com a informatização, com o digital.

Topamos com outras formas de textualização, de escrita e de leitura, cuja relação com a língua se desloca. As letras não se inscrevem mais sobre o papiro, nem é cópia, nem se escrevem, tampouco, com os esteriotipos da imprensa: hoje há uma variedade enorme de materiais e o escrito se faz na tela. Falo do digital, falo do computador e dos objetos digitais. $\mathrm{O}$ escrito dispõe, atualmente, de reservas imensas, impensáveis em quantidade, da memória metálica. O que a tela dá a ler, diz Cerquiglini, "é a tomada momentânea, a visualização efêmera de espaços textuais diferentes e móveis". Nesse lugar, o homem põe uma combinatória infindável de sinais à qual se liga. Dados. Não o gesto da mão na tinta, nem o traço feito no papel, mas impulsos elétricos/eletrônicos. Outra materialidade da variança, que faz mexer nossa forma de pensar o texto, a escrita. E, no caso de quem faz Letras, de pensar aí também a presença da língua. Nessas novas formas mantém-se a incompletude, embora a vontade de um dizer completo, total, se reforce, na ilusão da quantidade. Mas a linguagem não é transparente. Serve para comunicar, e para não comunicar, para dizer e para silenciar. Está sempre incompleta.

Muda, sim, o textual, na possibilidade da máquina e da memória metálica, a do computador. Muda a materialidade dos gestos de leitura. Mas o homem existe com suas relações de poder, com o jogo da ideologia, que, segundo pensamos, produz evidências onde não há, dando forma às relações sociais. E mesmo na dinâmica e na invisibilidade, ele busca significar o sim ou o não, o x ou o y (pense-se aqui na palavra amor e seus muitos sentidos; ou na palavra democracia). Porque relações de linguagem, relações de sentidos são relações de poder, que juntam, separam, dividem. E atribuem-se valores às divisões. Na nossa área de estudos, sabemos que não são todos que vão à escola. Para uns, as Letras, a escola, a escrita. Para outros, a falta. Mas a linguagem não para e, assim, formam-se outras manifestações da escrita, da textualização, do dizer: a pixação, a tatuagem, os símbolos. Também novas formas de música invadindo com seus sentidos o corpo dos sujeitos e o corpo social.

$\mathrm{Na}$ falta de condições para ter sua página em branco na escola, no modo como se constituem sujeitos do conhecimento, este sujeito cria sua letra e inscreve-se simbolicamente no social que o ignora. Chamado de vândalo, ele resiste e se diz artista. 
Ele é, na realidade, artista. Artesão de si, ele se cria no seu traço, na sua letra, pois esta é a sua entrada social visível no simbólico. A letra se avizinha ao grafismo. No muro, a pixação não transmite um "conteúdo". É sua forma mesma de estabelecer-se com sua letra outra, fora do regime da alfabetização que dá ao sujeito identidade e sentido. O que significa ler e escrever nesta relação com a pixação, o grafite? Que separação é esta entre saber e não saber a língua, a escrita?

As músicas como o rap também são textos, inscrições na existência, com seus modos de significar, à margem. Processos de linguagem que criam distância e criam vínculos. Manifestações da necessidade social. Todos temos necessidade dos laços sociais, pois somos seres simbólicos e sociais.

Considero, por outro lado, que também nosso corpo é um corpo atado ao corpo social. Nesse percurso, em que pensamos a pixação e o grafismo, nos aproximamos do que chamo (ORLANDI, 2001) letra encarnada. Funcionamento em que o próprio corpo é lugar da significação com letras, traços, grafismo. A textualização do corpo é uma prática acentuada atual. Prática em que estes gestos mostram a migração das marcas ritualísticas da letra e sua metaforização da identidade: piercing, tatuagem, e mesmo o tag. De um lado, a tentativa, vã, de enquadrar o corpo em seus limites, de outro, a denúncia de um mal-estar simbólico (de linguagem), uma forma de reivindicação. Uma mexida na Letra e no corpo simbólico.

Desse modo, pensando a conjuntura contemporânea, do estudo das Letras, do nosso curso de Letras, sabemos que o conhecimento das Letras inclui a abrangência da língua e da literatura, tomando a língua na sua relação tanto com as tecnologias da linguagem - as tradicionais e as novas - assim como outras manifestações da linguagem. Desse ponto de vista, considerando a língua enquanto condição do desenvolvimento das discursividades - seja de que material de linguagem for - ela é um importante lugar para se observar e poder mexer com esta conjuntura. Aprender em um curso de Letras, hoje, não é só saber como a língua é, como ela funciona, mas também como ela está presente na conjuntura em que funcionam as diferentes formas de linguagem. Assim, em retorno, compreendemos como estas outras formas de linguagem afetam a estrutura e o funcionamento da língua em suas aberturas, falhas, contradições e possíveis. Nossas L(1)etras se movem entre outras, entre nós e outros sujeitos, e até entre nós e nós mesmos, constituindo-nos com nossos sentidos. Tudo isso em movimento, em um processo em que nada já está pronto e acabado, embora pareça (efeito de evidência), e as Letras, a língua, se buscamos conhecê-la no meio e não apartada do funcionamento das Letras, é um lugar importante para se observar e poder interferir, mexer, com esta conjuntura, como dissemos. Em suma, entre o sujeito e ele mesmo; entre os sujeitos; entre os sujeitos e o mundo: a língua nos constitui. É ela o dedo que aponta para nossa existência (e para os sentidos que damos a ela), no mundo.

\section{REFERÊNCIAS}

CERQUIGLINI, B. Éloge de la variante: histoire critique de la philologie. Paris : Seuil, 1989. 
ORLANDI, E.P. Ciência da Linguagem e Política - anotações ao pé das Letras. Campinas: Pontes, 2014.

; FERREIRA, E. Os sentidos da inclusão. Niterói: Intertexto, 2010.

Língua Brasileira e outras histórias. Campinas: RG, 2009.

Língua e conhecimento linguístico: por uma história das ideias no Brasil. São Paulo: Cortez, 2002.

PÊCHEUX, M.; GADET, F. Langue Introuvable. Paris: Maspero, 1981.

RAMOS, G. Memórias do Cárcere. Rio de Janeiro: José Olympio, 1953.

Artigo recebido em: fevereiro de 2018.

Aprovado e revisado em: abril de 2018.

Publicado em: maio de 2018.

\section{Para citar este texto:}

ORLANDI, Eni Puccinelli. Entre Letras, o Mundo. Entremeios [Revista de Estudos do Discurso, ISSN 2179-3514, on-line, www.entremeios.inf.br], Seção Estudos, Programa de Pós-Graduação em Ciências da Linguagem (PPGCL), Universidade do Vale do Sapucaí (UNIVÁS), Pouso Alegre (MG), vol. 16, p. 219-227, jan. - jun. 2018.

DOI: http://dx.doi.org/10.20337/ISSN2179-3514revistaENTREMEIOSvol16pagina219a227 